\title{
Pengaruh Penerapan Pembelajaran Problem Based Learning (PBL) melalui Mathematical Modelling Terhadap Self Efficacy Anak Usia Dini
}

\author{
Mira Mayasarokh, Ita Yusritawati \\ Prodi Pendidikan Guru Pendidikan Anak Usia Dini, Prodi Pendidikan Matematika \\ STKIP Muhammadiyah Kuningan \\ mira@upmk.ac.id
}

\section{Info Artikel \\ Sejarah Artikel: Diterima (Juli) (2020) Disetujui (Juli) (2020) Dipublikasikan (Juli) (2020)}

\section{Keywords:}

Problem Based Learing (PBL); Mathematical Modelling; Self Efficacy

\begin{abstract}
Abstrak
Penelitian ini bertujuan untuk mengetahui pengaruh penerapan Pembelajaran Problem Based Learning (PBL) melalui mathematical modelling terhadap kepercayaan diri anak usia dini. Metode yang digunakan dalam penelitian ini adalah Mixed Method Strategi Embedded konkuren. Populasi dalam penelitian ini adalah siswa KB Plamboyan. Sampel penelitian terdiri dari siswa kelas B1 sebagai kelas kontrol, siswa kelas B2 sebagai kelas eksperimen 1. Instrumen yang digunakan dalam penelitian ini adalah tes dan non tes.Tes yang digunakan berupa tes tipe uraian sebanyak 6 soal. Non tes yang digunakan berupa angket skala Self Efficacy dijabarkan dan dieksplorasi dari 4 domain yakni: (1) domain motivasi, (2) domain kognisi, (3) domain perilaku, dan (4) domain emosi, dan lembar observasi serta wawancara mengenai kegiatan pembelajaran matematika dengan menggunakan pembelajaran Problem Based Learning (PBL) melalui Mathematical Modelling. Berdasarkan hasil analisis data hasil penelitian diperoleh kesimpulan: (1). Kepercayaan diri/self efficacy siswa yang memperoleh model pembelajaran Problem Based Learning $(P B L)$ melalui Mathematical Modelling lebih baik daripada pembelajaran konvensional. (2). Adanya perubahan kepercayaan diri siswa yang lebih baik walaupun belum begitu maksimal.
\end{abstract}

\begin{abstract}
This study aimed to develop mathematical problem solving skills andselfefficacy of students of Madrasah Tsanawiyah. By its method, thisresearch was a Mixed Method strategy embedded concurrent research. Thepopulation in this study were students of KB Plamboyan. While the samples were class B1 as the control class, class B2 as the experimental. The instruments used in this study were test and non-test. The testused was in the form of 6 description type questions. The non-testsused were in the form of a questionnaire, to scale Students' Self Efficacy outlined and explored from 4 domains: (1) motivation domain,(2) cognition domain, (3) behavioral domain, and (4) emotion domain.Another non-tests were sheets of observations and interview ofmathematics learning activities using Problem Based Learning (PBL)model through mathematical Modelling. Based on the analysis results, the conclusions obtained are: (1). Students' Self Efficacy capability ofthose who received learning with PBL model through Mathematical Modelling were better than those with conventional learning; (2). There were changes of better Self Efficacy in students, althoughhave not reached into maximum level.
\end{abstract}




\section{Pendahuluan}

Pendidikan memiliki peran penting dalam menghasilkan sumber daya manusia yang berkualitas dan memiliki daya saing dalam berbagai bidang, terutama ilmu pengetahuan dan teknologi yang sekarang ini berkembang secara cepat. Oleh karena itu, penyelenggaraan pendidikan harus dilaksanakan dengan maksimal sehingga tercapainya tujuan dari penyelenggaraan pendidikan itu sendiri. Sebagai mata pelajaran yang di pelajari pada setiap jenjang pendidikan, matematika memiliki tujuan seperti yang tercantum dalam Permendikbud Nomor 64 Tahun 2013 tentang standar isi pendidikan dasar dan menengah bahwa pelajaran matematika bertujuan agar peserta didik memiliki kemampuan diantaranya sebagai berikut (Permendikbud No 64, 2013): 1) menunjukkan sikap logis, kritis, analitis, cermat dan teliti, bertanggung jawab, responsif, dan tidak mudah menyerah dalam memecahkan masalah, 2) memiliki rasa ingin tahu, percaya diri, dan ketertarikan pada matematika, dan 3) menggunakan simbol dalam pemodelan, mengidentifikasi informasi, menggunakan strategi lain bila tidak berhasil

Berdasarkan hal tersebut, terdapat aspek lain yang juga memberikan pengaruh yang signifikan yaitu aspek psikologis. Aspek psikologis tersebut adalah self-efficacy atau kepercayaan diri, aspek ini merupakan salah satu bagian penting dalam pembelajaran, karena selama berlangsungnya kegiatan pembelajaran menuntut adanya perubahan sikap dan perilaku dalam diri siswa dan dapat meningkatkan kemampuan matematika siswa (Dewanto dalam Aisyah, 2012) Menurut Bouffrad-Bouchard selfefficacy juga berperan dalam kaitannya dengan pemodelan dan pemecahan masalah (Dewanto dalam Aisyah, 2012).

Selain merupakan bentuk refleksi kemampuan pemecahan masalah matematika siswa terhadap soal-soal pemecahan masalah yang dipelajari, self efficacy juga merupakan salah satu cara untuk meningkatkan kemampuan pemecahan masalah matematika siswa terhadap soal-soal pemecahan masalah matematika yang dipelajari. Dengan berdiskusi, menjelaskan ide, situasi, dan relasi matematika dalam bahasa sendiri baik secara lisan maupun tulisan siswa dapat mempertajam ide dan memperoleh informasi dari orang lain. Sehingga kemampuan pemecahan masalah matematika siswayang dipelajarinya akan meningkat. 
Berdasarkan fakta-fakta hasil penelitian di atas, untuk meningkatkan kemampuan self-efficacy/ kepercayaan diri matematika siswa, salah satu upaya yang dapat dilakukan oleh tenaga pendidik adalah melakukan inovasi dalam kegiatan pembelajaran. Tentunya hal itu juga dapat berpengaruh terhadap perubahan sikap. Perubahan sikap yang meliputi sikap pada materi pembelajaran (aspek kognitif) dan aspek afektif. Sebagaimana diutarakan oleh lester (dalam Aisyah, 2012) bahwa belajar adalah upaya untuk memperoleh kebiasaan-kebiasaan, pengetahuan, dan sikap-sikap. Oleh karena itu, proses belajar berlangsung dalam jangka waktu lama melalui latihan maupun pengalaman yang membawa kepada perubahan diri.

Sebagaimana disarankan oleh Ausubel (Ruseffendi, 2006) bahwa sebaiknya dalam pembelajaran digunakan pendekatan yang menggunakan metode pemecahan masalah, inkuiri dan metode belajar yang dapat menumbuhkan berpikir kreatif dan kritis, sehingga siswa mampu menghubungkan/mengaitkan dan memecahkan masalah matematis, pelajaran lainnya ataupun masalah yang berkaitan dengan kehidupan nyata. Dalam proses mengembangkan kemampuan Self Efficacy/kepercayaan diri anak usia dini tidaklah mudah. Banyak hal yang harus dipertimbangkan terkait psikologis anak, cara belajar anak, metode pembelajaran, strategi pembelajaran yang cocok ditrapkan pada anak usia dini.

Dari hasil penelitian sebelumnya menunjukan bahwa kemampuan pemecahan masalah matematika dan Self Efficacy/kepercayaan diri anak masih perlu ditingkatkan. Salah satu cara untuk mengatasi masalah tersebut adalah dengan melakukan inovasi dalam pembelajaran matematika, dengan menggunakan pendekatan-pendekatan pembelajaran yang dapat mengembangkan kemampua Self Efficacy/kepercayaan diri anak.Karena adanya kebutuhan untuk menyelesaikan permasalahan maka lahirlah suatu pemikiran atau ide matematika. Ruseffendi (1991) menyatakan bahwa matematika timbul karena pikiran-pikiran yang berhubungan dengan ide, proses, dan penalaran. Oleh karena itu konsep-konsep matematika berawal dari pengalaman dan kejadian dalam kehidupan manusia.Oleh karena itu siswa harus diberi kesempatan untuk menjalani suatu tahap konkrit. Pengertian konkrit disini, tidak hanya sebatas bahwa siswa bisa melihat, meraba akan model konkrit dari konsep yang akan dipelajari, tetapi juga anak dapat menangkap akan adanya situasi yang konkrit bagi anak. Hal ini sejalan dengan pendekatan pembelajaran pada anak usia dini, yaitu pendekatan saintifik. 
Dalam mengatasi permasalahan inilah, para guru selalu memerlukan metode pengajaran yang inovatif. Berbagai upaya dapat diusahakan oleh pengajar, diantaranya dapat dengan memberikan media pembelajaran yang baik, atau dengan memberikan model mengajar yang sesuai bagi siswa.Dari beberapa model pembelajaran dalam kurikulum 2013 yaitu model pembelajaran Problem Based Learning (PBL), model pembelajaran ini merupakan sebuah model pembelajaran yang menyajikan masalah kontekstual sehingga merangsang siswa untuk belajar. Metode ini memiliki kecocokan terhadap konsep inovasi pendidikan terutama dalam hal peserta didik memperoleh pengalaman dasar (basic sciences) yang berguna untuk memecahkan masalah. Dalam kelas yang menerapkan pembelajaran berbasis masalah, siswa bekerja dalam tim untuk memecahkan masalah dunia nyata (real word).

Model pembelajaran Problem Based Learning (PBL) berlandaskan pada psikologi kognitif, sehingga fokus pengajaran tidak begitu banyak pada apa yang sedang dilakukan siswa, melainkan kepada apa yang sedang mereka pikirkan pada saat mereka melakukan kegiatan itu. Pada Problem Based Learning (PBL) peran guru lebih berperan sebagai pembimbing dan fasilitator sehingga siswa belajar berpikir dan memecahkan masalah mereka sendiri. Dalam pembelajaran pengetahuan tertentu tentunya akan selalu ada model yang dapat ditiru. Model ini membantu siswa untuk menyelesaikan masalah yang ada. Mathematical Modelling merupakan salah satu metode pengajaran yang dapat digunakan sebagai pendekatan bagi para siswa agar untuk mengatasi masalah siswa pada pelajaran matematika, karena pendekatan ini membantu siswa untuk membuat/menggambarkan suatu model yang merepresentasikan masalah matematika untuk membantu mereka memvisualisasikan dan menyelesaikan masalah tersebut (CPDD, 2009).

Konsep matematika pada anak usia dini dapat dikenalkan dalam kegiatan seharihari, diantaranya dengan mengenalkan angka melalui membilang, mencocokkan, membandingka. Anak juga dapat dikenalkan konsep geometri serta dikenalkan konsep memilih dan mengelompokkan benda melalui bermain. Dari pemaparan diatas, dengan kata lain Mathematical Modelling memulai segala sesuatunya dengan masalah-masalah dunia nyata yang ingin ditemukan solusinya dengan mengubahnya ke dalam pemodelan matematika. Melalui Mathematical Modelling, siswa belajar untuk menggunakan berbagai macam pemecahan masalah dan memilih serta menerapkan secara tepat metode matematika dan menggunakannya dalam menyelesaikan dunia nyata. 
Berdasarkan latar belakang yang dijelaskan di atas, maka untuk mengembangkan kemampuan self efficacy/ kepercayaan diri pada anak usia dini dalam penelitian ini diterapkan pembelajaran Problem Based Learning (PBL) dan model pembelajaran Problem Based Learning melalui Mathematical Modelling.

\section{Metode Penelitian}

Metode penelitian yang digunakan dalam penelitian ini menggunakan Mixed Method Strategi Embedded konkuren. Strategi Embedded konkuren memiliki metode primer yang memandu proyek dan database sekunder yang memainkan peran pendukung dalam prosedur-prosedur penelitian. Metode sekunder yang kurang diproritaskan (kuantitatif atau kualitatif) ditancapkan (embedded) atau disarangkan (nested) kedalam metode yang lebih dominan (kualitatif atau kuantitatif) (Creswell, 2010).

Dengan demikian desain penelitian yang digunakan dalam penelitian ini adalah desain yang melibatkan tiga kelompok dengan pretes dan postes desain penelitiannya seperti berikut: (Ruseffendi, 2005: 50)

$\begin{array}{lll}0 & X_{1} & 0 \\ 0 & & 0\end{array}$

Keterangan:

0 : Pretes/postes kemampuan pemecahan masalah matematika

$\mathrm{X}_{1}$ : Kelas Ekperimen yang memperoleh perlakuan (pembelajaran menggunakan model pembelajaran Problem Based Learning (PBL) melalui Mathematical Modelling)

Penelitian ini akan dilaksanakan di Kelompok Bermain Plamboyan Desa Ragawacana Kabupaten Kuningan. Populasi yang diambil yaitu siswa kelas B, sampel yang di ambil dalam penelitian terdiri dari tiga kelas, yaitu kelas pertama adalah kelas B1 sebagai kelas kontrol, kelas B2 sebagai kelas eksperimen 1.

\section{Hasil Penelitian}

Untuk menjawab rumusan masalah, apakah Self Efficacy siswa mengalami penurunan setelah mendapatkan pembelajaran matematika dengan menggunakan model pembelajaran Problem Based Learning (PBL) melalui Mathematical Modelling biasa maka dikumpulkan data Self Efficacy siswa melalui angket skala Self Efficacy yang 
diberikan kepada kelas eksperimen dan kelas kontrol pada akhir pembelajaran atau sesudah diberikan perlakuan. Maka kita harus terlebih dahulu mengetahui kemampuan Self Efficacy awal siswa.

\section{Hasil}

Analisis Data Angket Awal Self Efficacy siswa

Tabel 1. Analisis Angket Awal Skala Self Efficacy Siswa Kelas Eksperimen dan Kelas Kontrol

\begin{tabular}{|c|c|c|c|c|c|}
\hline \multirow[t]{2}{*}{ Kelas } & \multicolumn{5}{|c|}{ Skor Angket Awal } \\
\hline & $\mathbf{N}$ & SMI & $\begin{array}{c}\text { Nilai } \\
\text { Maksimum }\end{array}$ & $\begin{array}{c}\text { Nilai } \\
\text { Minimum }\end{array}$ & Rerata \\
\hline Kontrol & 40 & 100 & 90 & 55 & 70,70 \\
\hline Eksperimen & 40 & 100 & 89 & 54 & 71,70 \\
\hline
\end{tabular}

Berdasarkan Tabel di atas terlihat bahwa rerata skala Self Efficacy siswa pada awal pembelajran di kelas eksperimen sebesar 71,70, dan kelas kontrol sebesar 70,70 .

Tabel. 2 Hasil Uji Normalitas Data Angket Awal Self Efficacy Siswa

\begin{tabular}{llccc}
\hline & Kelas & \multicolumn{3}{c}{ Kolmogorov-Smirnov } \\
& & Statisti & df & Sig. \\
& & $\mathrm{c}$ & & \\
Angket_a & Kontrol & .133 & 40 & .073 \\
wal & Eksperime & .089 & 40 & $.200^{*}$ \\
& $\mathrm{n}$ & & & \\
\hline
\end{tabular}

Berdasarkan Tabel diatas menggunakan uji Kolmogorov-Smirnova signifikansi data angket Self Efficacy awal pembelajaran di kelas eksperimen adalah 0.200 dan signifikansi data angket untuk kelas kontrol adalah 0,073, kedua kelompok > 0,05 maka ini menunjukkan bahwa kedua kelas berasal dari populasi 
yang berdistribusi normal (Trihendradi, 2008). Langkah selanjutnya menguji homogenitas varians, untuk menguji homogenitas varians digunakan uji Levene.

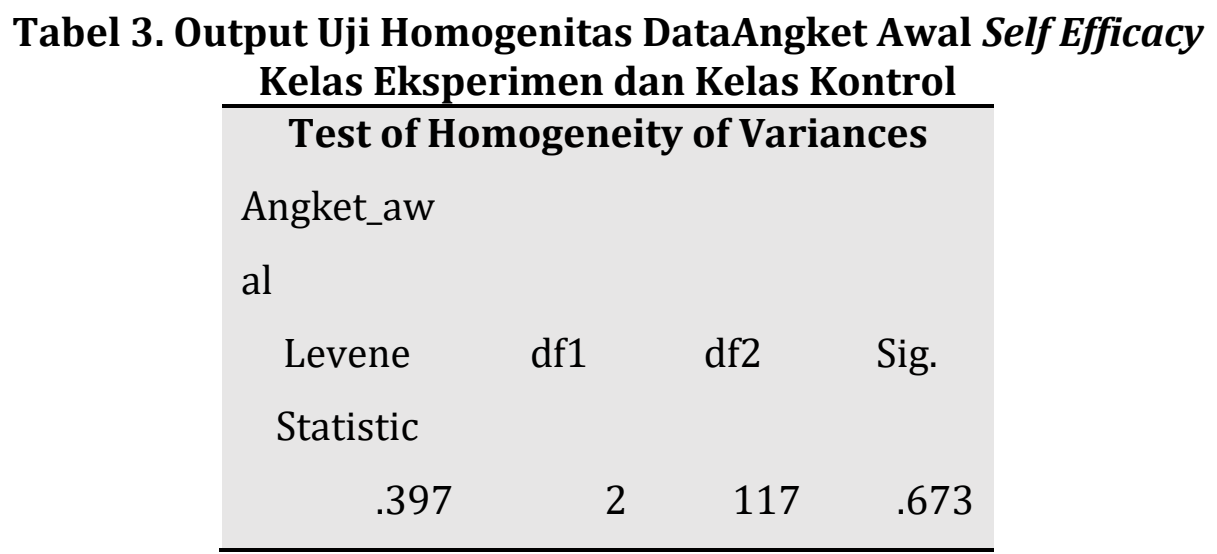

Karena nilai signifikasi yang diperoleh 0,673 $>0,05$ maka $\mathrm{H}_{0}$ diterima, sehingga data kedua kelas tersebut homogen. Karena data tersebut normal dan homogen, maka langkah selanjutnya yang dilakukan adalah menganalisis dengan One-Way Anova.

$\begin{array}{lccccc}\text { Tabel 4. Hasil Uji Anova Satu JalurData Angket Awal Self Efficacy siswa } \\ \begin{array}{l}\text { Kelas Eksperimen dan Kelas Kontrol } \\ \text { Angket_awal }\end{array} & \begin{array}{l}\text { Sum of } \\ \text { Squares }\end{array} & \text { Df } & \text { Mean } & \text { F } & \text { Sig. } \\ & 1036.817 & & \text { Square } & & \\ \text { Between } & & & 518.408 & 9.389 & .000 \\ \text { Groups } & 6460.175 & 117 & 55.215 & & \\ \text { Within } & & & & & \\ \text { Groups } & 7496.992 & 119 & & & \\ \text { Total } & & & & & \\ \end{array}$

BerdasarkanTabel di atas terlihat bahwa nilai sig bernilai 0,000 artinya $H_{a}$, diterima sehingga terdapat perbedaan Self Efficacy siswa secara signifikan diantara kedua kelas.

\section{Analisis Data Angket Akhir Self Efficacy}

Hasil data angket akhir Self Efficacy siswa dianalisis untuk mengetahui Self Efficacy siswa sesudah dilakukan penelitian. Tahap pertama yang dilakukan adalah analisis deskriptif data sebagai berikut: 
Tabel 5. Analisis Statistik Deskriptif Data Angket Akhir Self Efficacy Kelas Eksperimen dan Kelas Kontrol

\begin{tabular}{cccccc}
\hline Kelas & \multicolumn{5}{c}{ Nilai Tes Akhir (Postes) } \\
& N & SMI & Nilai & Nilai & Rerata \\
& & & Maksimum & Minimum & \\
Kontrol & 40 & 100 & 96 & 74 & 83.72 \\
& & & & 96 & 102.82 \\
\hline
\end{tabular}

Berdasarkan Tabel bahwa rata-rata data angket akhir Self Efficacy siswa untuk kelas eksperimen adalah102,82 lebih unggul dibandingkan kelas kontrol adalah 83,72. Selanjutnya diilakukan tahap kedua yaitu uji statistik diantaranya uji normalitas dan homogenitas.

Tabel 6. Output Uji Normalitas Data Angket Akhir Self Efficacy

Kelompok Eksperimen dan Kelompok Kontrol

\begin{tabular}{llcrr}
\hline & Kelas & \multicolumn{3}{c}{ Kolmogorov-Smirnov } \\
& & Statisti & Df & Sig. \\
& & c & & \\
Angket_Ak & Kontrol & .122 & 40 & .138 \\
hir & Eksperime & .090 & 40 & $.200^{*}$ \\
& $\mathrm{n}$ & & & \\
\hline
\end{tabular}

Berdasarkan Tabel di atas menggunakan uji Kolmogorov-Smirnov ${ }^{a}$ signifikansi data angket akhir Self Efficacykelas eksperimen adalah 0.200; dan nilai signifikansi untuk kelas kontrol adalah 0,138, kedua kelompok >0,05 maka ini menunjukkan bahwa kedua kelas berasal dari populasi yang berdistribusi normal (Trihendradi, 2008). Langkah selanjutnya menguji homogenitas varians, untuk menguji homogenitas varians digunakan uji Levene, sebagai berikut: 
Tabel 7. Output Uji Homogenitas DataAngket Akhir Self Efficacy Kelompok Eksperimen dan Kelompok Kontrol Test of Homogeneity of Variances

Angket_Akhi

$r$

Levene df1 df2 Sig.

Statistic

$\begin{array}{llll}1.775 & 2 & 117 \quad .174\end{array}$

Karena nilai signifikasi yang diperoleh 0,174 > 0,05 maka $\mathrm{H}_{0}$ diterima, sehingga data kedua kelas tersebut homogen. Karena data tersebut normal dan homogen, maka langkah selanjutnya yang dilakukan adalah menganalisis dengan One-Way Anova.

Tabel 8. Hasil Uji Anova Satu Jalur Data Angket Akhir Self Efficacy Kelas Eksperimen dan Kelas Kontrol

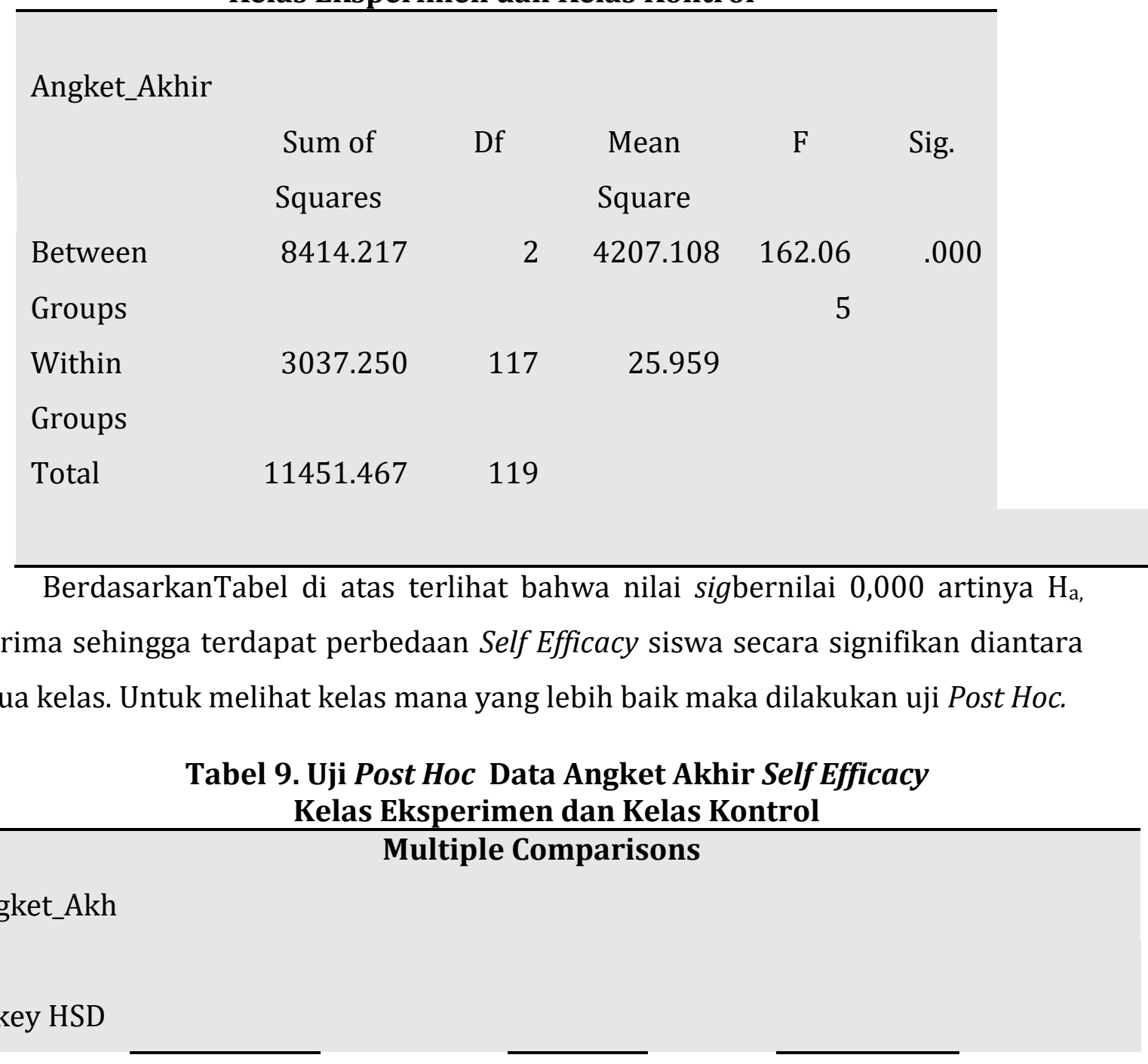




\begin{tabular}{llccccc}
\hline (I) Kelas & (J) Kelas & $\begin{array}{c}\text { Mean } \\
\text { Difference }\end{array}$ & Std. & Sig. & \multicolumn{2}{c}{ 95\% Confidence Interval } \\
& & & & Lower & Upper \\
& & & & Bound & Bound \\
Kontrol & Eksperime & $-19.10000^{*}$ & 1.1392 & .000 & -21.8046 & -16.3954 \\
& n 1 & 8 & & & \\
*. The mean difference is significant at the 0.05 & & & \\
level.
\end{tabular}

Berdasarkan Tabel 4.23 maka diperoleh:

(Kelas Kontrol dan Kelas Eksperimen)

Nilai sig $=0,000<0,005$ maka $H_{a}$ diterima, artinya kelas eksperimen 1 lebih baik dari kelas kontrol.

\section{Analisis Gain Ternormalisasi Self Efficacy Siswa}

Hasil data gain ternormalisasi dianalisis untuk mengetahui peningkatan angket Self Efficacy pada awal dan akhir pembelajaran yang menggunakan Problem Based Learning (PBL) melalui Mathematical Modelling, dan konvensional. Tahap awal yang dilakukan adalah analisis deskriptif data sebagai berikut:

Tabel 10. Gain Ternormalisasi Data Self Efficacy Kelas Eksperimen dan Kelas Kontrol

\begin{tabular}{|c|c|c|c|c|c|c|c|}
\hline \multicolumn{8}{|c|}{ Descriptive Statistics } \\
\hline & $\mathrm{N}$ & Range & $\begin{array}{l}\text { Minim } \\
\text { um }\end{array}$ & $\begin{array}{l}\text { Maxim } \\
\text { um }\end{array}$ & Mean & $\begin{array}{c}\text { Std. } \\
\text { Deviation }\end{array}$ & $\begin{array}{c}\text { Varian } \\
\text { ce }\end{array}$ \\
\hline $\begin{array}{l}\text { GainEksperi } \\
\text { men }\end{array}$ & 40 & .73 & .84 & 1.57 & $\begin{array}{r}1.121 \\
0\end{array}$ & .17788 & .032 \\
\hline Gain & 119 & .70 & .24 & .94 & .5966 & .16947 & .029 \\
\hline GainKontrol & 40 & 1.17 & -.30 & .73 & .4000 & .28319 & .08 \\
\hline KelasGain & 120 & 2.00 & 1.00 & 3.00 & $\begin{array}{r}2.000 \\
0\end{array}$ & .81992 & .672 \\
\hline $\begin{array}{l}\text { Valid N } \\
\text { (listwise) }\end{array}$ & 40 & & & & & & \\
\hline
\end{tabular}


Berdasarkan Tabel di atas, rerata gain ternormalisasi kelas eksperimen, dan kelas kontrol berbeda. Rerata gain normal kelas eksperimen $(1,1210)$ lebih tinggi dibandingkan kelas kontrol (0,4000). Berdasarkan kriteria Hake (1999:1) N-gain kelas eksperimen berada pada kategori tinggi, dan kelas kontrol berada pada kategori sedang. Untuk melihat peningkatannya signifikan atau tidak, maka dilakukan tahap kedua yaitu analisis statistik parametrik, diantaranya uji normalitas dan homogenitas data.

\section{Tabel 11. Hasil Uji Normalitas Data Gain TernormalisasiAngket Self Efficacy}

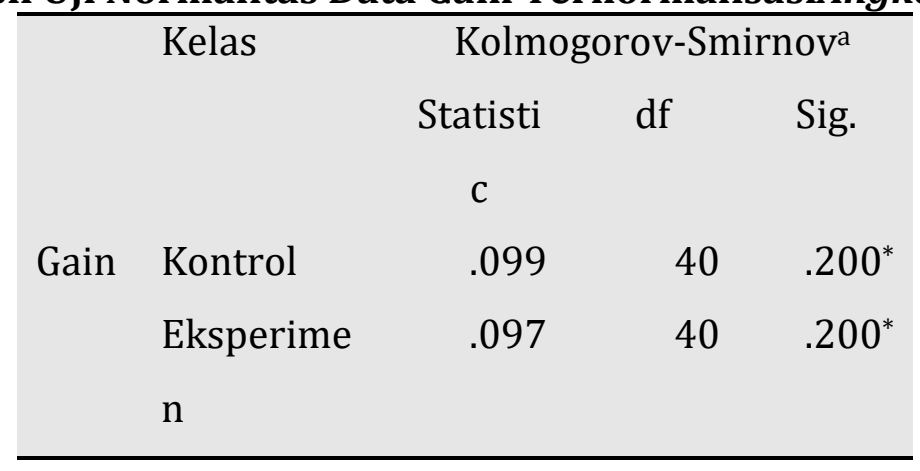

Berdasarkan Tabel di atas menggunakan uji Kolmogorov-Smirnova signifikansi data gain kelas eksperimen adalah 0.200 , dan signifikansi data gain untuk kelas kontrol adalah 0,200. Karena kedua kelompok > 0,05 maka ini menunjukkan bahwa kedua kelas berdistribusi normal (Trihendradi, 2008). Langkah selanjutnya menguji homogenitas varians, untuk menguji homogenitas varians digunakan uji Levene, sebagai berikut:

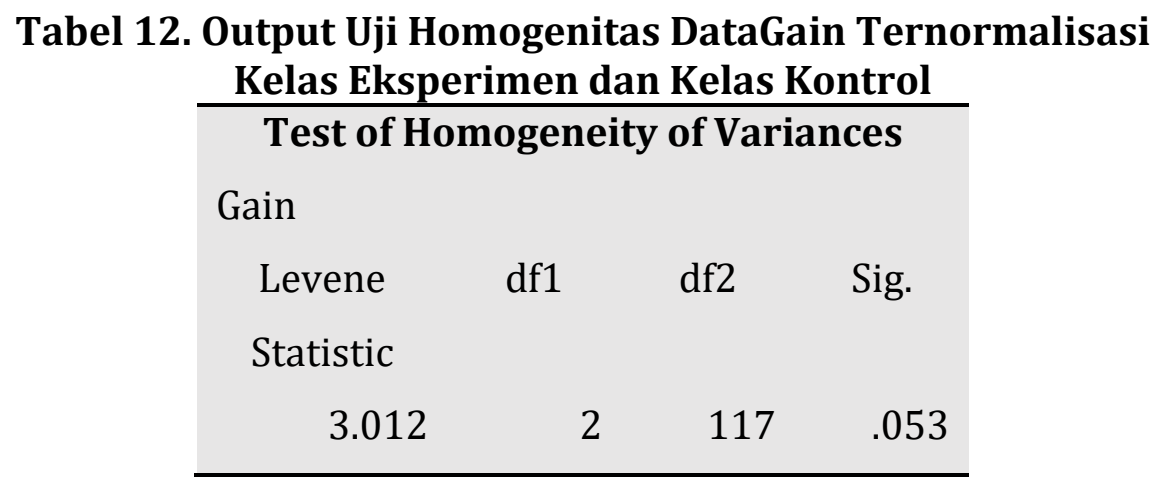

Karena nilai signifikasi yang diperoleh $0,053>0,05$ maka $\mathrm{H}_{0}$ diterima, artinya kedua kelas tersebut homogen. Langkah selanjutnya yang dilakukan adalah menganalisis dengan One-Way Anova. 
Tabel 13. Hasil Uji Anova Satu JalurData N-Gain Self Efficacy

Kelas Eksperimen dan Kelas Kontrol

\begin{tabular}{|c|c|c|c|c|c|}
\hline \multicolumn{6}{|c|}{ ANOVA } \\
\hline & $\begin{array}{l}\text { Sum of } \\
\text { Squares }\end{array}$ & Df & $\begin{array}{c}\text { Mean } \\
\text { Square }\end{array}$ & $\mathrm{F}$ & Sig. \\
\hline Between & 11.866 & 2 & 5.933 & 89.642 & .000 \\
\hline \multicolumn{6}{|l|}{ Groups } \\
\hline Within & 7.744 & 117 & .066 & & \\
\hline \multicolumn{6}{|l|}{ Groups } \\
\hline Total & 19.610 & 119 & & & \\
\hline
\end{tabular}

Berdasarkan Tabel di atas terlihat bahwa nilai sig bernilai 0,000 artinya $\mathrm{H}_{\mathrm{a}}$, diterima sehingga terdapat perbedaan rerata N-Gain Self Efficacy siswa diantara kedua kelas. Untuk melihat mana peningkatan yang lebih baik diantara kedua kelas digunakan uji Post Hoc.

Tabel 14. Uji Post Hoc Gain TernormalisasiSelf Efficacy

Kelas Eksperimen dan Kelas Kontrol Multiple Comparisons

Gain

Tukey HSD

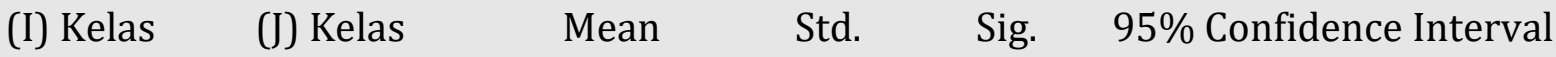
Difference Error Lower Upper

(I-J) Bound Bound

$\begin{array}{lllllll}\text { Kontrol } & \text { Eksperime } & -.72100^{*} & .05753 & .000 & -.8576 & -.5844\end{array}$

$\mathrm{n}$

*. The mean difference is significant at the 0.05

level.

Berdasarkan Tabel di atas diperoleh: (Kelas Kontrol dan Kelas Eksperimen) Nilai sig $0,00<0,05$ maka $H_{a}$ diterima, artinya rerata peningkatan kelas eksperimen lebih baik dari kelas kontrol. 


\section{Diskusi}

Melihat aktivitas di kelas dari setiap pertemuan terutama dalam setiap 10 menit kesatu sampai keempat terjadi perubahan yang lebih baik. Pada 10 menit pertama dan kedua aktivitas siswa mulai muncul pada pertemuan kedua, dikarenakan hal ini perlu adaftasi dengan model pembelajaran yang digunakan. Kemudian pada setiap 10 menit mulai pertemuan ketiga siswa sudah aktif belajar mandiri baik dengan teman kelompok ataupun antar kelompok, presentsai yang dilakukan lebih antusias pada 10 menit ketiga mulai dari pertemuan ketiga dan selanjutnya.

Dari wawancara yang telah dilakukan kepada guru dengan pertanyaanpertanyaan yang menyangkut kegiatan atau aktivitas selama pembelajaran berlangsung baik di kelas eksperimen maupun kelas kontrol, menghasilkan bahwa siswa mengalami perubahan dalam aktivitas belajar, terutama mengenai rasa kepercayaan diri yang terus bertambah sehingga lebih mulai banyak ide-ide untuk menyelesaikan soal-soal pemecahan masalah. Minat dalam belajarpun dirasakan bertambah serta kebiasaan dalam belajarpun mulai berubah semakin baik dan dirasakan kerjasama antar teman terutama dalam kelompok hal ini memberikan suatu kontribusi kepada siswa untuk memiliki rasa kebersamaan dan tanggung jawab yang baik. Dengan demikian bahwa dari hasil wawancara dan juga observasi dapat memberikan jawaban mengenai 4 domain yang ada dalam angket Self Efficacy diantara 4 doamin tersebut yaitu: domain motivasi, domain kognisi, domain perilaku (behavior), dan domain emosi.

\section{Simpulan}

Berdasarkan analisis, hasil penelitian dan pembahasan yang sudah diungkapkan, dapat di simpulkan, Kemampuan Self Efficacy siswa yang memperoleh model pembelajaran Problemt Based Learning (PBL) melalui Mathematical Modelling lebih baik daripada kemampuan siswa yang memperoleh pembelajaran matematika secara konvensional. Dari wawancara yang telah dilakukan kepada guru dengan pertanyaanpertanyaan yang menyangkut kegiatan atau aktivitas selama pembelajaran berlangsung baik di kelas eksperimen maupun kelas kontrol, menghasilkan bahwa siswa mengalami perubahan dalam aktivitas belajar, terutama mengenai rasa kepercayaan diri yang terus bertambah sehingga lebih mulai banyak ide-ide untuk menyelesaikan soal-soal pemecahan masalah. Minat dalam belajarpun dirasakan bertambah serta kebiasaan 
dalam belajarpun mulai berubah semakin baik dan dirasakan kerjasama antar teman terutama dalam kelompok hal ini memberikan suatu kontribusi kepada siswa untuk memiliki rasa kebersamaan dan tanggung jawab yang baik. Dengan demikian bahwa dari hasil wawancara dan juga observasi dapat memberikan jawaban mengenai 4 domain yang ada dalam angket Self Efficacy diantara 4 domain tersebut yaitu: domain motivasi, domain kognisi, domain perilaku (behavior), dan domain emosi.

\section{Daftar Pustaka}

Aisyah, S. (2012). Meningkatkan Kemampuan dan Pemecahan Masalah Matematis Melalui Mathematicall Modelling. Tesis pada PPS UPI: Tidak diterbitkan.

Bandura, A. (2006). Guide For Constructing Self-efficacy Scales. Self-efficacy Beliefs of Adolescents, researt journal volume 6, 307-337.

CPDD. (2009). The Singapore Model Method for Learning Mathematics. Singapore: EPB Pan Pasific.

Depdiknas (2003). Undang-Undang Sistem Pendidikan Nasional no 20, Jakarta: DEPDIKNAS.

(2006). Permendiknas no 22 tahun 2006 tentang standar isi Sekolah Menengah Atas, Jakarta: DEPDIKNAS.

Franz, et. al. (2007).National Impact: Creating Teacher Leader Through the Use of Problem Based Learning. National Forum of Apllied Education Research Journal Volume 20, Number 3.

Hake, R. R. (1999). Interactive Engagement Versus Traditional Method: A Six Thousand Student Survey of Mechanics Test Data for Introductory Physics Course.American Journal Physics. 66. 64-74.

Indrawan, R. \& Yaniawati, P (2014).Metodelogi Penelitian: Kuantitaf, Kualitatif, dan Campuran untuk Manajemen, Pembangunan, dan Pendidikan. Bandung: Refika Aditama.

Kementrian Pendidikan dan Kebudayaan.(2013).Modul Pelatihan Implementasi Kurikulum 2013 SMP/MTs Matematika. Jakarta: Badan Pengembangan Sumber Daya Manusia Pendidikan dan Kebudayaandan Penjaminan Mutu Pendidikan Kementerian Pendidikan dan Kebudayaan 2013.

Meltzer, D. E. (2002). The Relationship Between Mathematics Preparation and Conceptual Learning Gain in Physics: A Possible "Hidden Variable" in Diagnostic Pretest Scores. American Journal of Physics [Online].Tersedia: http://www.physics iastate.edu/per/docs/AJP-Des-2002-Vo.70. 1259-1268.pdf. [17 Pebruari 2016] 
Ruseffendi, E.T. (1991). Penilaian Pendidikan dan Hasil Belajar Siswa Khususnya dalam Pengajaran Matematika untuk Guru dan Calon Guru. Bandung: Tarsito.

(2006). Pengantar kepada Membantu Guru Mengembangkan Kompetensinya dalam Pengajaran Matematiak untuk Meningkatkan CBSA. Bandung: Tarsito.

Suherman, E. (2003). Evaluasi Pembelajaran Matematika. Bandung: FPMIPA UPI.

Trihendradi, C. (2008). 7 Langkah Mudah Melakukan Analisis Statistik Menggunakan SPSS 17. Yogyakarta: CV.Andi Offset 